\title{
TRTaKaDEMi
}

ISSN 2149-9446 | Cilt 06 | Sayı 11 | Ocak 2021 |Büyük Veri

\section{"Büyük Verinin Gücü Adına": Siyasi Kampanyalarda Etkili Veri Kullanımı}

\section{ILGAR SEYIDOV}

\begin{abstract}
Öz
İki binli yılların başlamasıyla Web 2.0 uygulamalarının yaygınlaşması, akıllı telefonların üretimi, yeni iletişim teknolojileri, arama motorları gibi veri depolama ve kullanımı araçlarının artması ile birlikte veri bolluğu ve çeşitliliği ortaya çıkmıştır. "Büyük Veri" olarak adlandırılan bu geniş ölçekli devasa bilgi hazinesi; sosyal, kültürel ve siyasal anlamda değişimlerin de oluşmasına ve geleneksel anlayışların yeni biçimler kazanmasına neden olmuştur. Siyasal iletişim anlayışı çerçevesinde verileşme ile birlikte "veri odaklı" siyasi kampanya kavramı tartışılmaya başlanmıştı. Veri odaklı kampanyacılık, çeşitli veri kümelerinin toplanılması, analiz edilmesi ve tahminsel modellerin oluşturulmasıyla yürütülen sistematik bir süreçtir. Bu anlamda ABD'deki seçimlerde ilk uygulamaları görülse de diğer ülkelerde de yayılmaktadır. Türkiye bağlamında da yeni bir anlayış olan veri odaklı siyasal kampanyacılığın temelini etkili veri kullanımı oluşturmaktadır. Yapılan bu çalışma ile büyük veri ile birlikte yeni biçim kazanan siyasal kampanya süreci hem kuramsal hem de çeşitli örnekler üzerinden ele alınmaktadır. Bu anlamda veri odaklı kampanyacılık anlayışı detaylı literatür taraması ile farklı perspektifler üzerinden tartışılmaktadır. Daha sonra farklı ülkelerde gerçekleştirilen veri odaklı kampanyalardan örnekler verilerek verinin ne şekilde ve hangi amaçlarla kulanıldığı gösterilmektedir. Son olarak, çalışmada kavram haritası tekniğinden yararlanılarak siyasal kampanyalarda etkili veri kullanımına ilişkin bir yol haritası önerilmektedir.
\end{abstract}

Anahtar Kelimeler: Büyük Veri, Veri Kullanımı, Verileşme, Veri Odaklı Siyasal Kampanyalar

\section{Derleme}

Geliş Tarihi: 30.09.2020

Kabul Tarihi: 06.01.2021

ORCID ID: 0000-0001-8420-1413 DOI: 10.37679/trta.802534

E-mail: ilgar.seyidov@atilim.edu.tr 


\title{
TRTaKaDEMi
}

ISSN 2149-9446 | Volume 06 | Issue 11 | January 2021 | Big Data

\section{"For the Sake of Big Data": Effective Data Use in Political Campaigns}

\author{
ILGAR SEYIDOV
}

\begin{abstract}
By the 2000s proliferation of Web 2.0 applications, production of smart mobile phones, new communication technologies, search engines and such data store and use devices have led to emergence of data abundance and variety. Big Data has brought about social, cultural and political changes and new scientific forms through its sophisticated structure. One of them is "data-driven campaigning", which has started to be discussed within political communication by the effect of verification process. Data-driven campaigning refers to the process that is conducted through the data collection, analysis and formation of predictive models which focuses on political attitudes and behaviors of citizens. The elections in 2012 and 2016 are the first examples of data-driven politicla campaigns. Since then the data use has become prevalent in other regions. Data and its effective use is essential for this sort of campaigns. The current study analyzes data-driven campaigning theoretically and by referring to different cases. In addition, the study aims to draw a road map for data-driven political campaigning.
\end{abstract}

Keywords: Big Data, Data Use, Datafication, Data-Driven Political Campaigning

Composition

Recieved: 30.09 .2020

Accepted: 06.01.2021

ORCID ID: 0000-0001-8420-1413 DOI: 10.37679/trta.802534

E-mail: ilgar.seyidov@atilim.edu.tr 


\section{Giriş}

Yirmi birinci yüzyılın ikinci yarısında hızla gelişen teknoloji, yazılım sistemi ve internetle birlikte ortaya çıkan dijital uygulamalar ve platformların yaygın kullanımı önemli ölçüde sosyal, toplumsal ve kültürel değişimlere neden olmuştur. Özellikle çok sayıda ve türde bilginin dijital sistemler aracılığıyla açık hâle gelmesi ve kullanıma açılması, beraberinde yeni tartışmaları getirmiştir. Bu anlamda tartışma konularının başında veri bolluğu, ölçeği ve karmaşıklığı gibi özellikleri içeren "büyük veri" anlayışı gelmektedir.

Aslında büyük veri kavramı, kökenini bilgisayar terminolojisinden almaktadır. Temel olarak standart ve yazılım süreçlerinin hafiza boyutunu aşan kompleks veri kümelerini kapsayan bir anlayış olarak tanımlanmaktadır (Lewis ve Westlund, 2015: 448). Bu anlamda çeşitli çevrim içi işlemler, videolar, görseller, ses, e-mail, tıklama dizisi, bildirimler, arama motorları, bilimsel veri, sensör ve uygulamalar örnek olarak gösterilebilir. Tüm bu kaynaklar, devamlı gelişen ve büyüyen bir veri tabanında depolanmaktadır. Bu çeşitliliği ve ölçütü veri tabanını "büyük” kılmaktadır. Bu bağlamda büyük veri anlayışı hem doğa bilimleri hem de sosyal bilimlerde farklı yaklaşımlarla tartışılmaktadır (Sağıroğlu ve Sinanc, 2013: 43).

Büyük verinin teknik olarak kavramsallaşttrılması literatürde " 3 Vs" olarak da bilinen üç ana öge üzerine kuruludur: hacim (volume), hız (velocity) ve çeşitlilik (variety). Hacim, verinin tutarı ya da miktarı ile ilişkiliyken hı, verinin eklenme ve işlenme hızı ile ilgilidir. Çeşitlilik ise verinin geldiği çoklu kaynakları ve kullanıldığı farklı biçim ve yapıları ifade etmektedir (Moffat-Hannah, 2019: 457). Olgular, semboller ya da sinyaller, yani değişebilen ve etkileşimli yapay olgular büyük veri çerçevesinde örnek gösterilebilir. Başka bir ifadeyle büyük veri; genel anlamda dijital yapıların çokluğunu, kullanıcı odaklı çevrim içi içeriği, verileşme sonuçlarını, sensör, dron ve benzeri araçlar aracılığıyla aktarılan ve yayılan sinyalleri, çevrim içi takipleri, meta verileri vs. süreçleri içeren bir anlayıştır (Guiterrez, 2018: 4).

Sayısız çeşitli veriyi barındıran bir kapasitesi olması nedeniyle tüm verilerin analiz edilmesi imkânsızdır. Veri çokluğu, çeşitliliği, süresizliği, dinamizmi, yüksek rasyonalitesi ve belirsizliği temel zorluklar olarak ortaya çıkmaktadır. Ancak bu zorluklar bir taraftan da bilim insanlarına daha sofistike ve geniş ölçekli bir bilimsel modeli geliştirmelerine olanak sunmaktadır (Kitchin, 2014: 2-7). Büyük veri ile ilgili tartışmaların en önemli noktalarından biri de bu geniş ölçekli veri kümelerinin kullanılmasının sosyal, kültürel, siyasi ve hukuki değişimler ve dönüşümler için etkili olduğudur. Diğer bir ifadeyle büyük veri anlayışı aynı zamanda verileşme süreci aracılığıyla verileşen sosyal dünyayı anlamak ve deneyimlemek amacını da içermektedir (Breiter ve Hepp, 2018: 392). Bu nedenle Rubinstein'e (2014: 864) 
göre sözü geçen " $3 V^{\prime}$ ” tek başına sosyal bilimler için yeterli değildir. Dördüncü bir "V" olarak değer kavramının büyük veri ile ilgili tartışmalarda önemi vardır.

Verileşme sürecinin etkilediği olgulardan biri de iletişim sistemi ve dolayısıyla iletişim ile ilişkili alanlardır. Büyük veri ve verileşme süreci çerçevesinde siyasal iletişim anlayışında son yıllarda "veri demokrasisi", "veri vatandaşlığı", "veri aktivizmi" ve "veri odaklı kampanyalar" gibi kavramlar tartışılmaktadır. Veri kullanımı ile birlikte üretilen bu anlayışlar hem kuramsal olarak hem de çeşitli örnek olaylar üzerinden incelenmektedir. Sınırlı sayıda çalışılmakta olan konulardan biri de siyasal kampanyalarda veri kullanımı ve etkisidir. Bu çalışma, literatürde hem kuramsal hem de uygulamalı olarak yeni çalışılmakta olan bir konuyu, "veri odaklı siyasal kampanyalar" anlayışını temel almaktadır. Türkiye'de ilgili literatür incelendiğinde genel anlamda sosyal medyanın seçim süreçlerinde nasıl kullanıldığına (İkiz vd. 2014; Evren, 2015; Balcı ve Sarıtaş, 2015; Zararsız ve Sönmez, 2018; İnanç vd. 2020) odaklanıldığı görülmektedir. Bu çalışmalarda seçim süreçlerinde yürütülen kampanyalarda sosyal medya kullanımının siyasal katılımı nasıl etkilediği geniş olarak ele alınmaktadır. Diğer taraftan, verileşme süreci ile birlikte siyasal kampanyalarda veri kullanımına ilişkin kapsamlı bir çalışmaya rastlanmamaktadır. Sadece bir çalışmada (Zeybek, 2020) siyasal kampanyalarda veri temelli yönelimler, genel bakış açısıyla farklı veri analizi yöntemlerine değinilerek ele alınmıştır. Bu anlamda önerilen bu çalışma sadece verileşme ile birlikte değişen siyasal kampanya sürecini literatür taraması aracılı̆̆ıyla hem kuramsal hem de farklı ülke örnekleriyle ele almamakta, aynı zamanda gelecek çalışmalar ve uygulamalar için etkili veri kullanımına ilişkin yol haritası önermektedir. Çalışmanın temel sorunsalı olan siyasal kampanyalarda veri kullanımı üç ana başlıkta tartışılmaktadır. Öncelikle veri odaklı siyasi kampanyacılık anlayışının ne olduğu kavramsal olarak tartş̧ılmaktadır. Daha sonra belirli örnekler üzerinden verinin hangi olanakları sağladığına odaklanılmaktadır. Son olarak kavram haritası tekniği ile gelecekteki çalışmalar ya da kampanyalar için veri kullanımına ilişkin yol haritası önerilmektedir.

\section{Veri Odaklı Siyasal Kampanyacılık Anlayışı}

Bilgi, her zaman siyasi kampanyalar için önemli kaynak olmuş, 1900'lerin ilk yıllarından başlayarak geniş şekilde tartışılan "kamuoyu" kavramı ve sonradan ABD'de uygulanan kamuoyu araştırmaları, politikacıların kitlelerin oy davranışları ve tercihleri ile ilgili bilgi edinmesinde etkin rol oynamıştır. Dönemsel gelişmeler ve süreçlerle siyasal kampanyalar yeni kuramsal ve uygulamalı biçimler kazanmıştır. Illetişim araçları, teknolojik gelişmeler ve hedef kitle algısının değişmesiyle 
birlikte yeniden şekillenmiştir. Özellikle parti odaklı kampanyalardan birey odaklı kampanyalara evrilen süreci daha iyi anlamak amacıyla Magin vd. (2017: 1700) şu şekilde bir tablo hazırlamıştır:

Tablo 1. Siyasal Kampanyaların Tarihsel Aşamaları

\begin{tabular}{|l|l|l|l|l|}
\hline $\begin{array}{l}\text { Kampanya } \\
\text { Türü }\end{array}$ & Dönem & $\begin{array}{l}\text { Ana iletişim } \\
\text { Aracı }\end{array}$ & Hedef Kitle & $\begin{array}{l}\text { En son kullanılan } \\
\text { Kampanya araçları }\end{array}$ \\
\hline $\begin{array}{l}\text { Parti Odaklı } \\
\text { Kampanyalar }\end{array}$ & $\begin{array}{l}1850 \text { ve } 1960 \\
\text { yılları arasında }\end{array}$ & $\begin{array}{l}\text { Basın ve Yüz Yüze } \\
\text { Etkileşim }\end{array}$ & $\begin{array}{l}\text { Partizanlar } \\
\text { ve Parti } \\
\text { Üyeleri }\end{array}$ & $\begin{array}{l}\text { Medya desteği, } \\
\text { toplantılar, mitingler, } \\
\text { piyadeler }\end{array}$ \\
\hline $\begin{array}{l}\text { Kitle Odaklı } \\
\text { Kampanyalar }\end{array}$ & $\begin{array}{l}1960 \text { ve } 1990 \\
\text { yılları arasında }\end{array}$ & $\begin{array}{l}\text { Sınırlı Tek Kanallı } \\
\text { Televizyon Yayını }\end{array}$ & Kitleler & $\begin{array}{l}\text { Uydu yayınları, te- } \\
\text { levizyon haberleri, } \\
\text { mitingler, reklamlar, } \\
\text { anketler }\end{array}$ \\
\hline $\begin{array}{l}\text { Hedef Kitle } \\
\text { Odaklı Kam- } \\
\text { panyalar }\end{array}$ & $\begin{array}{l}1990 \text { ve } 2008 \\
\text { yılları arasında }\end{array}$ & $\begin{array}{l}\text { Çok Kanallı TV } \\
\text { Yayını ve Internet } \\
\text { (Web 1.0) }\end{array}$ & $\begin{array}{l}\text { Hedef Kitle } \\
\text { Grupları }\end{array}$ & $\begin{array}{l}\text { Internet ve } \\
\text { doğrudan mail }\end{array}$ \\
\hline $\begin{array}{l}\text { birey Odaklı } \\
\text { Kampanyalar }\end{array}$ & $\begin{array}{l}2008 \text { yılından } \\
\text { itibaren }\end{array}$ & $\begin{array}{l}\text { Çok Kanallı TV } \\
\text { Yayını ve Internet } \\
8 \text { Web 2.0) }\end{array}$ & Bireyler & $\begin{array}{l}\text { Web 2.0 platformları } \\
\text { ve dijital uygula- } \\
\text { malar }\end{array}$ \\
\hline
\end{tabular}

Tablo 1'de görüldüğü üzere, 2000'li yıllarla birlikte birey odaklı kampanyalarda bireye yönelik bir hedef kitle anlayışı hâkimken, iletişim araçları ise internete bağlı Web 2.0 uygulamaları ve dijital platformlar seçilmiştir. İnternetin yaygınlaşması, verinin farklı kategoriler altında yeniden şekillenerek "kullanıcı-yönelimli" oluşmasına neden olmuştur. Bu da siyasal kampanyalarda da kullanıcı odaklı verilerin kullanılması için zemin yaratmıştır. Diğer taraftan "ağ analizi” daha çok kişiye kısa zamanda ulaşılmasıyla daha kolay hâle gelmiştir. Büyük verinin sunduğu bilgi hazinesinden yararlanmak, algoritmaları kontrol ederek görünürlüğü artırmak, paylaşım ve sosyal medya akışını belirleyerek internette daha çok ziyaret platformuna dönüşmek ve bu verileri siyasi kampanyalar için kullanmak önemli faktörler olarak ortaya çıkmıştrr (Tüfekçi, 2014: 16). Veri, enformasyon toplumunun "motorunu" çalıştıran temel kaynaktır. Özellikle büyük veri tartışmaları içerisinde farklı kaynaklarla veriye erişim ve kullanım şekli- karar verme ve hizmet sağlama anlamında- stratejik iletişimin bir alanı hâline dönüşmüştür (Wiessenberg vd. 2017: 95).

Modern kampanyalarda veri, farklı özellikleriyle kullanılabilmektedir. Temel amaç, seçim sonucuna ilişkin geleceği öngörmek ve oy verme potansiyeline sahip listeye ulaşabilmek ve bu listedeki kişilerle irtibat kurabilmektir (Nickerson ve Rogers, 2014: 53). Veri odaklı kampanyacılık anlayışı, büyük ölçekli veri kümelerinin spesifik kitlelere ulaşmada, mesajları iletmede ve mesajların etkisini artırmada kullanımını içermektedir (Baldwin-Phillipi, 2019: 2). Özellikle, Kuzey Amerika'da veri odaklı 
kampanyaları gelişmekte ve artmaktadır. Bu kampanyalarda oy verenlerin kişisel verilerinin kullanılmasıyla siyasal davranışları ve etkileşim düzeyleri temel alınmaktadır. Avrupa ülkelerinde ise kişisel verilerin gizliliği ve korunması ile ilgili kapsamlı yasal düzenlemelerden dolayı veri odaklı kampanyalar daha yavaş ve farklı açılarda gelişmektedir (Bennett, 2016). Amerika örneği üzerinden Kreiss (2016), veri kullanımı için öncelikle siyasal kampanyaların dört önemli bileşeninin altını çizmektedir: (1) Kaynaklar (bütçe ve gönüllülük sayısı), (2) Altyapısal faktörler (partinin teknolojik becerileri ve araçları), (3) Kurumsal yapı (kurum kültürü ve yapısı) ve (4) Seçimsel döngü faktörleri (seçim sonuçlarının değerlendirilmesi). Bu bağlamda Dobber ve arkadaşlarına (2017: 2-3) göre teknolojinin sağladığı firsatlarla büyük veri dünyasında oy verme potansiyeline sahip kişiler ile ilgili bilgi toplama ve analiz etme, modern siyasal kampanyaların daha başarılı ve etkin sonuçlara ulaşmasına katkı sağlamaktadır. Örneğin, sosyal medya sadece bir iletişim ya da sözde sosyalleşme aracı değildir. Aynı zamanda kullanıcılarının davranışsal verilerine ulaşma ve bunu anlayabilme aracıdır. Bu anlamda reklam piyasasında bilinen bir teknik olan "davranışsal hedef belirleme" yönteminden yararlanılarak siyasal tutum ve davranışlar çözümlenebilir. Reklam sektöründe ajansların tüketici verilerine ulaşma ve onların çevrim içi davranışlarını ölçme amacıyla kullandığı bu teknik ve tüketici veri tabanından siyasal kampanyalar sürecinde faydalanılabilir. Ancak elbette kişisel verilerin gizlilik ihlali de önemli bir sorun hâline gelebilir.

Veri odaklı kampanyalar iki önemli ve makro düzeyli özelliği içermektedir: hedefleme ve test etme. Hedefleme, kampanya sürecinde hangi potansiyel oy verenlere hangi mesajların iletilmesi gerektiğine karar verme süreci iken; test etme, bu mesajların nasıl etki/tepki doğurduğu, içerik üretimi ve hedefleme ile ilgili ampirik bir çözümlemedir (Baldwin-Phillipi, 2017: 628). Hedefleme çerçevesinde verilerin toplanması önemli bir süreçtir. Bir önceki seçim sonuçları, oy kayıtları, nüfus verisi, parti ya da kampanya veri tabanları, sosyal medya verileri, tüketicilerin yaşam tarzları ile ilgili veriler, sosyal grafik verisi, algoritmik gruplandırmalar vs. sayısız veri kaynakları farklı stratejilere yönelik olarak kullanılabilmektedir. Bu veriler ya parti tarafindan toplanmakta ya da üçüncü taraflardan (Örneğin, ABD'de Catalyst, Aristotle, NationBuilding gibi veri firmaları var.) alınmaktadır. Toplanan mesajların hedef kitleye uygun hâle getirilmesi amacıyla test edilmesi için ise TargetSmart, Targeted Victory gibi çeşitli veri programları vardır (Baldwin-Phillipi, 2019: 3).

Günümüzde çeşitli veri toplama araçları ve sistemleri vardır. Genelde siyasi partiler geçmiş seçim sonuçlarını temel veri tabanları olarak kullanmaktadır. Geleneksel yöntemler hâlâ fazlasıyla etkilidir. Ancak modern dönemde veri toplama, analiz etme ve kullanmada çeşitli yöntemler ve sistemler mevcuttur. Bu anlamda 
en büyük sorun ise uzman bilgi eksikliği ve veri korunmasına ilişkin yasa düzenleme eksikliğidir (Kruschinski, 2017: 15-16). Artkk veriler, akıllı telefonlardaki özel yazılımlar aracılığıyla daha kolay şekilde toplanmaktadır. WLAN erişim noktasına bağlanıldığı anda, toplanan veriler hizmet noktasına otomatik olarak aktarılmaktadır. Kiukkonen ve arkadaşlarına (2010) göre kullanıcılardan toplanan veriler şöyle kategorize edilmektedir:

- Sosyal etkileşim verisi (Arama günlüklerinden, kısa mesaj kayıtlarından ve bluetooth tarama sonuçlarından elde edilmektedir.)

- Lokasyon verisi (GPS'e bağlı durum, mobil ağ ve WLAN erişim noktalarından gelen bilgilerden elde edilmektedir.)

- Medya tüketimi verisi (video/fotoğraf ile çekilen ya da müzik çalınan/paylaşılan lokasyonlardan gelen bilgilerden elde edilmektedir.)

- Davranışsal veri (mobil uygulama kullanımı, etkinlik algılama sensörleri, düzenli cihaz kulanımı istatistikleri, arama ve mesaj kayıtlarına bağlı bilgilerden elde edilmektedir.)

Bu verilerden yararlanılarak siyasal kampanyalarda veri uzmanı ve alanında yetkin ekip üyeleri tarafindan tahminlere yönelik modeller oluşturulmaktadır. Oluşturulan modeller temelde üç ana faktör üzerinde durmaktadır. illki, daha önceki davranış ve demografik bilgilerin kullanılmasıyla kişilerin gelecek siyasal davranışlarının tahmin edilmesine ilişkin davranışsal sonuçlardır. İkincisi, bireysel değil toplu ihtimallere dayalı vatandaşların siyasi tercihlerini anlamaya yönelik destek verilerdir. Son olarak vatandaşların kampanya faaliyetlerine nasıl tepki vereceğini ve nasıl yönetebileceğine ilişkin kampanya öncesi yapılan test çalışmasını içeren çözüm oluşturma sürecidir (Nickerson ve Rogers, 2014: 54).

Genel anlamda veri kullanımı siyasal kampanyalara enformasyon açısından sosyal medya ve diğer çevrim içi kaynaklardan geniş ölçekli verilere ulaşma ve yurttaşların tutum/davranışlarının tahmin edilmesine yönelik modelleştirme sunarken iletişim/ etkileşim açısından hızlı ve etkin şekilde iletilen hedef odaklı bir iletişim stratejisinin hazırlanmasına katkı sağlamaktadır. Diğer taraftan kampanya sürecinin izlenilme ve değerlendirilmesi açısından mesajları test etme teknikleri (örneğin, $A / B$ testi), kullanıcı yanıtlarını izleme oranları, sosyal medya ölçü bilimi, gerçek zamanlı etki ölçme yöntemi gibi özellikler sunmaktadır (Dommett, 2019: 3-4).

\section{Veri Odaklı Kampanyalara İlişkin Örnekler}

Veri odaklı kampanya anlayışı büyük veri ile birlikte ortaya çıkan ve gelişmekte olan bir süreçtir. Bu anlamda daha çok ABD'de örneklere rastlanmaktadır. Avrupa'da $A B D$ 'den farklı olarak kişisel verilerin korunmasına ilişkin yasal düzenle- 
meler ve sıkı denetimin olması, veri odaklı kampanyaların daha farklı boyutlarda ve yavaş şekilde ilerlemesine neden olmaktadır. Siyasal kampanyalarda bireysel düzeyde oy verenlerin tüketim davranışları, medya tercihleri, demografik bilgileri gibi özellikler siyasi tutum ve davranışların tahmin edilmesinde önemli bir veri tabanı sağlamaktadır. Örneğin, Obama'nın 2008 yılı seçim kampanyasında 800 farklı oy verme potansiyeline sahip kişinin veri değişkeni kullanılarak spesifik gruplara yönelik bir mikro-hedefleme stratejisi belirlenmiştir. Mikro-hedefleme aslında ilk kez Bush'un 2004 yılı kampanyasında denenmiş ve başarılı olmuştur. Her iki kampanyanın başarılı olmasına neden olan faktör verilerin farklı değişkenler arasında doğru korelasyonun kurulması ve analiz edilmesidir (Northcott, 2020: 97-98). Bush ve Obama ile ABD'de başlayan ve daha sonra diğer ülkelerde de uygulanmaya başlanan veri odaklı kampanyalar incelendiğinde Birleşik Krallık, Almanya ve Kenya örnekleri ön plana çıkmaktadır.

\section{ABD Örneği}

2012 yılı Başkanlık seçimlerinde McCain'in kampanyası geleneksel anlayışta ve kitle iletişim medya araçlarına odaklanırken Obama'nın kampanya stratejisi, dijital medyanın etkin kullanımı üzerine kurulmuştur. Adaylardan Romney'in kampanya sürecinde de sosyal medya etkili şekilde kullanılmıştır. Square, Eventbrigh ve Facebook gibi dijital platformlar aktif olarak kullanılırken YouTube ve Hulu'dan reklamlar için yararlanılmıştır. Obama'da olduğu gibi Romney de Twitter'ı gerçek zamanlı paylaşım için kullanmıştır. Diğer adaylardan farklı olarak Obama'da "2012 Dashboard" isimli bir sosyal medya sitesi kurmuştur. Bu platform, yurttaşlara gönüllülük, hareketlilik ve katılım gibi fonskiyonlar sunmuştur. Akıllı telefonların hızla yaygınlaştığını gören kampanya yöneticisi Jim Messina, destekçilerin kolay şekilde küçük bağışlar yapabilmesi için kısa mesaj taktiğini uygulamıştır. 33 milyon Facebook ve 22 milyon Twitter takipçisi bulunan Obama'nın kampanya ekibi istatistik analizler gerçekleştirmiş ve dijital medya stratejisinde mahalle düzeyinde gruplar oluşturmuştur. Dashboard sitesinde tüm kullanıcılar mahalle grupları içine yerleştirilmiştir. Bu şekilde aynı mahalle ya da bölgeden kişiler de Obama'yı kimlerin desteklediğini fotoğraf ve videolarla görebilmiştir. Kampanya sürecinde Facebook'taki Obama destekçilerinin verileri gönüllülük için de kullanılmıştır. Facebook'ta Obama takipçilerine çekişmeli seçim bölgelerindeki arkadaşlarının profil bilgileri mesaj aracılığıyla iletilerek oy vermeleri için irtibata geçmeleri teşvik edilmiştir. Böylece veri kullanımı ve mikro-hedefleme ilk kez bu kampanyada etkili şekilde kullanılmış ve başarılı sonuçlar ortaya çıkarmıştır (Bimber, 2014). 
2016 Başkanlık seçimlerinde Trump’ın en büyük başarısı veri odaklı kampanya sürecinin doğru hedef grup belirleme ve etkili veri kullanımı ile yürütülmesi olmuştur. Trump'ın kampanya stratejisi kapsamında Facebook reklamları ile mikro-hedefleme, ekranlardaki kenar çubuğu reklamlarında belirli sıklıklarla görülme, Facebook'ta ilgi çekici kategoriler üzerinde gönderilerin eklenmesi gibi taktiklerle sağlandı. Reklamlar, Trump destekçilerine yönelik pozitif ve Clinton karşıtı negatif algıyı içermiştir. Cambridge Analytica, kampanyanın dijital danışmanlığını yapmıştır. Facebook reklamları için ayrılan ve harcanan bütçe, Clinton'un dijital reklamlara harcadığından üç kat daha fazla olmuştur. Bu mikro-hedefleme yöntemi çok iyi planlanmış ve uygulanmıştır (Baldwin-Phillipi, 2017). Ayrıca bu seçimde Cambridge Analytica tarafindan 50 milyon Facebook verisi kampanyalar kullanımı için satışa çıkarılmıştır. Bu detaylı veri, ilk başta akademik bir amaca yönelik Aleksander Kogan tarafindan geliştirilen "Thisisyourdigitallife" uygulaması aracılığıyla toplanmıştır. Daha sonra Cambridge Analytica bu veriyi almış ve kullanıma açmıştı (Karunian vd. 2019).

\section{Birleşik Krallık Örneği}

2015 yılındaki genel seçimlerde büyük partiler veri kullanımına odaklanırken küçük partiler Excell tablo kullanımı gibi daha az etkili yöntemleri tercih etmiştir. Bu seçim sürecinde Mosaic isimli posta kodu temelli veri tabanına sahip Experian şirketi tarafindan üretilmiş ve yüksek bir meblağ karşılığında kullanılmak üzere sunulmuştur. Bu veri tabanı, ülke popülasyonunun gelir, değer ve kültürel sermayelerine göre 67 kategoriye bölmüştür. Mosaic sistemine erişim pahalı olduğundan, sadece büyük partiler kullanabilmiştir. Bu anlamda Muhafazakârlar Partisi sisteme erişim sağlarken Sosyal Demokratlar kullanmamayı tercih etmiştir. Yeşiller Partisi, Mosaic sisteminden farklı bir seçim kapsamında destekçilerinin yaşadıkları bölge ve sosyoekonomik bilgilerini kullanmak amacıyla yararlanırken 2015 seçimlerinde kullanmamıştır. Küçük partiler ise finansal yetersizlikten dolayı kamuoyu araştırmaları, anketler vs. gibi geleneksel yöntemleri daha çok kullanmıştır. Büyük partilerin kampanya süreçlerinde veri uzmanları aktif olarak yer almıştır (Anstead, 2017).

\section{Almanya Örneği}

Almanya'da ABD ve Birleşik Krallık'tan farklı bir seçim sistemi vardır. Partiler daha eşit oranlarda ve köklü parti "kaleleri" ile temsil edilmektedir. Yine bahsi geçen ülkelerden farklı olarak Almanya'da kişisel verilerin gizliliği ve kullanımı ilgili yasal düzenlemelerle korunmaktadır. Bu nedenle Almanya'da siyasi kampanyalarda coğrafi hedef belirleme hâlâ fazlasıyla kullanılan bir modeldir. Özellikle büyük ve köklü partilerin etkili oldukları bölgelere göre hazırlanan bu stratejilerden dolayı küçük partilerin şansı azalmaktadır. Diğer taraftan 2016 Rhineland palatinliği parlamento 
seçimlerinde çevrim içi uygulamalar propagandist amaçlar doğrultusunda Sosyal Demokratlar tarafindan etkili şekilde kullanılırken Yeşiller Partisi harita ve not tutma yöntemlerine başvurmuştur. Sol Parti ise geleneksel metot olarak telefon aramalarına odaklanmıştır. Veri kullanımı anlamında ise bir önceki seçim ve mevcut seçim sürecinde "ev ziyaretleri", eski seçim sonuçları ve bu sonuçlara göre demografik verilerin karşılaştırılması etkili olmuştur. Her ne kadar Yeşiller Partisi "mobilizasyon endeksi" diye sözde yeni bir veri analizi kullandığını ifade etmiş olsa da aslında eski seçimlerde yapılan ev ziyaretlerinden elde edilen bilgilerin karşılaştırılarak potansiyel oy verenlerin tespiti ve yeniden ziyaret edilmesi amacını taşımıştır. Aynı zamanda Yeşiller Partisi Alman Posta'sını doğrudan mail için kullanmıştır. Aslında yeni veri analizi yöntemleri partiler tarafindan uygulansa da kullanılan, bir önceki seçimlerin sonuçları olmuştur. ABD'de olduğu gibi etkili bir veri odaklı kampanya süreci gerçekleştirilememiş olsa da 2016 Rhineland seçimlerinde ilk adımların atıldığı görülmüştür (Kruschinski, 2017).

\section{Kenya Örneği}

Kenya'da uzun yıllardır etnik bölücülük üzerine bir politika ve seçimle ilişkili şiddet olayları yaşanmaktadır. 2007 yılında yaklaşık 1.200 kişinin öldüğü, 600 bin kişinin etnik gruplar arası şiddet nedeniyle yaşadığı yerden zorla edildiği şaibeli seçim sürecinden sonra 2017 seçimlerinde de benzeri olayların yaşanmaması için çeşitli önlemler alınsa da Kenya Ulusal İnsan Hakları Komisyonu, 2017 seçimlerinde sadece 8 ve 12 Ağustos tarihleri arasında 24 kişinin öldürüldüğünü ifade etmiştir. İnsan Hakları İzleme Komitesi, seçim sürecinin son ayında ise 100 kişinin yaralandığını belirtmiştir. Yine şiddet olaylarının yaşandığı 2017 seçimleri ile ilgili Kenya'nın "The Star" gazetesi 2018 Mart ayında ünlü veri firması Cambridge Analytica'nın bahsi geçen seçim sürecinde aktif yer aldığını yazmıştır. Aday Kenyatta için Analytica'nın stratejisi etnik düşmanlığı artıran bir "bölücü propoganda" anlayışı üzerine kurulu olmuştur. Kampanya sürecinde Kenya vatandaşlarına oy kayıt bilgileri ile sosyal medya verileri ve telefon numaralarının birleştiği verilerin açığa çıktı̆ına dair spekülatif mesajlar yollanmıştır. Aynı zamanda telefonlarına belirli aralıklarla olabilecek saldırılar ile ilgili bildirimler ve rakip aday Raila Odinga'nın şiddet ve rüşvet yanlısı, tehlikeli bir politik figür olduğuyla ilgili bilgiler aktarılmıştır. Veri gizliliğin bu şekilde ihlali ve suistimalinin temel nedeni ise ilgili kanun ve yasal uygulamaların eksikliğidir. Bu anlamda Kenya örneği, verinin kanunsuz ve kötüye kullanımına ilişkin bir kampanya örneğidir (Karunian vd. 2019).

Diğer taraftan Güney Kore'de bire bir uygulanmış model olmasa da Noh (2013: 118-119) veri odaklı bir seçim kampanyası için üç aşamalı bir model önermekte- 
dir: Planlama, Uygulama ve Değerlendirme (Plan-Do-See). İlk aşama, büyük veriden yararlanılarak veri toplanır, seçim ortamı araştırılır, strateji belirlenir ve taktikler netleştirilir. Uygulama aşamasında ise mikro-hedefleme ve faaliyetler gerçekleşmektedir. Son aşamada etkileri değerlendirilmektedir. Basit bir anlatımla, "veri girişi-veri işlemi-veri analizi-kampanya stratejisi" şeklinde bir öneriyi sunmaktadır. Bu anlamda ülkede çeşitli veri analizi programları ve firmalarının bulunduğu sektöre dikkat çekilmektedir. Noh'un Güney Kore için önerdiği modelden farklı olarak bu çalışma, siyasi kampanyalarda hem etkili veri kullanımını anlamak hem de uygulamak için bir yol haritası önermektedir. Bu anlamda sonraki bölümde kuramsal olarak öne çıkarılan ve bu örneklerde uygulanan bazı taktikler temel alınarak bir öneri sunulmaktadır.

\section{Etkili Veri Kullanımı için Yol Haritası}

Veri; Wiessenberg, Zerfass ve Moreno'nun (2017) enformasyon toplumu için betimlediği gibi, siyasal kampanyaların "motorunun" temel "yakıt" kaynağıdır. Çünkü veri olmadan bir kampanya sürecinin sistematik yürütülmesi ve kayda değer sonuçlara ulaşması imkânsızdır. Buradaki veri anlayışı kişisel verilerden coğrafi konumlara kadar geniş bir yelpazeyi kapsamaktadır. Ancak temelde siyasi kampanyalar için oy verme potansiyeline sahip kişilerin verileri siyasi tutum ve davranışlarının çözümlenmesi açısından önemli bir yere sahiptir. Özellikle hedef belirleme stratejisi için elzemdir. Büyük veri ile birlikte veri bolluğu ve çeşitliliği, siyasal kampanya süreci için önemli firsatlar sunmaktadır. Dünyada ABD'de başlayan veri odaklı kampanyalar önceki bölümde görüldüğü üzere diğer ülkelerde de farklı yönleriyle yaygınlaşmaktadır. Türkiye'de daha çok sosyal medya kullanımı etkin ve popüler olsa da gittikçe büyük verinin diğer özelliklerinin de kullanımı ülkedeki genç nüfus dikkate alındığında yenilikçi ve yararlı olabilir. Bu anlamda verinin etkili kullanımı önemli bir aşamadır. Çalışma kapsamında etkili veri kullanımına yönelik genel hatlarıyla bir kavram haritası aşağıdaki şekilde gösterilebilir.

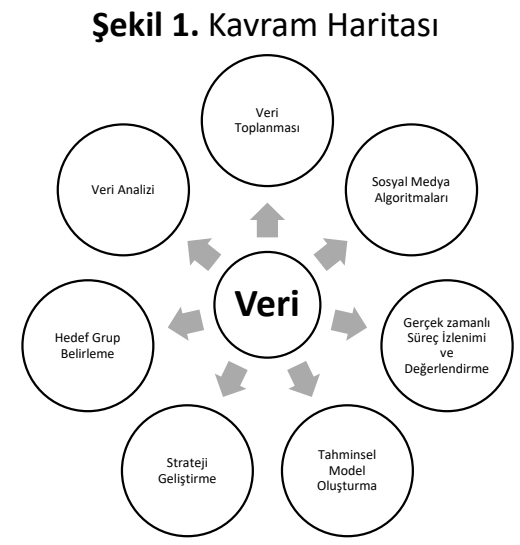


Şekil 1'de görüldüğü gibi, temelde yedi ana bileşen öne çıkmaktadır: veri toplanması, veri analizi, hedef grup belirleme, strateji geliştirme, tahminsel model oluşturma, sosyal medya algoritmaları ve gerçek zamanlı süreç izleme/değerlendirme. Veri toplanması ve analizi için örneklerde de bahsedildiği gibi çeşitli yöntemler ve teknikler vardır. Baldwin-Phillipi'nin (2019) belirttiği gibi, bir önceki seçim sonuçları, oy kayıtları, nüfus verisi, parti ya da kampanya veri tabanları, sosyal medya verileri, tüketicilerin yaşam tarzları ile ilgili veriler, sosyal grafik verisi, algoritmik gruplandırmalar vs. sayısız veri kaynakları farklı stratejilere yönelik olarak kullanılabilmektedir. Diğer taraftan Nickerson ve Rogers'ın (2014) vurguladığı gibi hedef grup belirleme, seçim sonucuna ilişkin geleceği öngörmek ve oy verme potansiyeline sahip listeye ulaşabilmek ve bu listedeki kişilerle irtibat kurabilmek amacıyla önemli bir aşamadır. Örneğin, sosyal medya sadece bir iletişim ya da sözde sosyalleşme aracı değildir. Aynı zamanda kullanıcılarının davranışsal verilerine ulaşma ve bunu anlayabilme aracıdır. Bu anlamda reklam piyasasında bilinen bir teknik olan "davranışsal hedef belirleme" yönteminden yararlanılarak siyasal tutum ve davranışlar çözümlenebilir (Dobber vd. 2017). Kampanya sürecinin bütünsel stratejisinin geliştirilmesinde verilerin analiz ve test edilmesiyle oluşturulan tahminsel modellerin önemli rolü vardır. Dommett'in (2019) ifade ettiği gibi, veri kullanımı siyasal kampanyalara enformasyon açısından sosyal medya ve diğer çevrim içi kaynaklardan geniş ölçekli verilere ulaşma ve yurttaşların tutum/davranışlarının tahmin edilmesine yönelik modelleştirme sunarken, iletişim/etkileşim açısından da hızlı ve etkin şekilde iletilen hedef odaklı bir iletişim stratejisinin hazırlanmasına katkı sağlamaktadır. Diğer taraftan kampanya sürecinin izlenilme ve değerlendirimesi açısından mesajları test etme teknikleri (örneğin, A/B testi), kullanıcı yanıtlarını izleme oranları, sosyal medya ölçü bilimi, kullanıcılarla etkileşimli biçimde kampanya sürecinin takibi ve sonuç değerlenidirilmesine ilişkin gerçek zamanlı etki ölçme yöntemi gibi özellikler veri odaklı kampanyaların son aşamasında sağlanılan yararlar olarak gösterilebilir. Özellikle sosyal medya algoritmasına odaklanılarak görünürlük oranının artırılması ve hedef gruba yönelik düzenli bildirim paylaşımı ABD'de Trump'ın kampanyasında en başarılı taktiklerden olmuştur (Baldwin-Phillipi, 2017; Karunian vd. 2019). 
Şekil 1'de gösterilen kavram haritasından yola çıkarak siyasi kampanyalarda verinin etkili kullanılmasına yönelik Noh'un (2014) Güney Kore için önerdiği modele benzer biçimde üç aşama belirlenebilir. Bu aşamalar Şekil 2'de detaylı olarak görülebilir.

Şekil 2. Etkili Veri Kullanımı Aşamaları

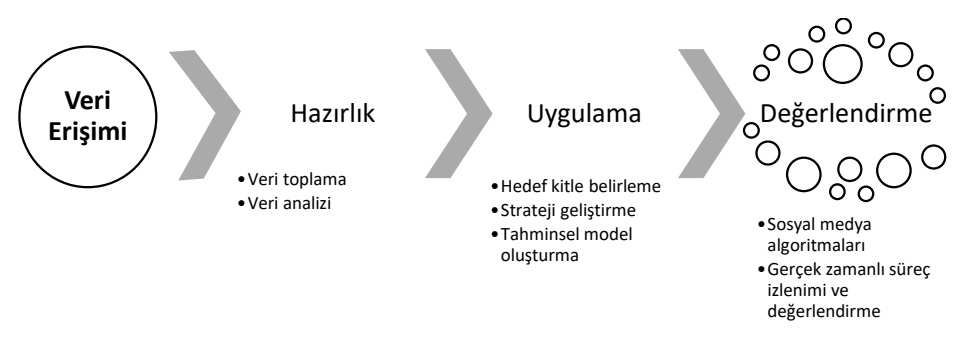

Şekil 2'de veriye erişim sağlanmasıyla başlayan üç aşama- hazırlık, uygulama ve değerlendirme- gösterilmektedir. Bu betimlemeye göre, veri toplanması ve analizi siyasi kampanyalarda hazırlık aşaması olarak başlamaktadır. Gerekli verilerin toplanılması ve analiz edilmesi sonucunda, uygulama aşamasına geçilmektedir. $\mathrm{Bu}$ anlamda oy verme potansiyeline sahip hedef kitlelerin belirlenmesi, mevcut stratejinin geliştirilmesi ve uzman ekipler tarafindan tahminsel modellerin oluşturulması gerçekleşmektedir. Son aşama, kampanya etkisinin artırılmasına yönelik sosyal medya algoritmalarının yönetilmesi ve genel sürecinin etkilerinin gerçek zamanlı izlenilmesi ile sonuçların gelecek seçimler için değerlendirilmesini içermektedir.

Etkili veri kullanımı için yol haritası belirlenirken dikkat edilmesi gereken noktalardan biri de altyapı konusudur. ABD örneğini temel alarak Kreiss (2016), veri kullanımı için öncelikle siyasal kampanyaların dört önemli bileşeninin altını çizmektedir: (1) Kaynaklar (bütçe ve gönüllülük sayısı); (2) Altyapısal faktörler (partinin teknolojik becerileri ve araçları); (3) Kurumsal yapı (kurum kültürü ve yapısı) ve (4) Seçimsel döngü faktörleri (seçim sonuçlarının değerlendirilmesi). Bu anlamda veri kullanımı için ciddi bir finansal destek gerekmektedir. En önemlisi ise alanında yetkin veri uzmanlarına ihtiyaç duyulmaktadır. İlgili programların kullanılması ve doğru analiz/tespitlerin yapılmasıyla tahminsel modellerin oluşturulması çok hassas bir süreçtir.

\section{Sonuç}

Büyük veri olgusu, 2000'li yıllarda internetin yaygınlaşması, iletişim teknolojilerinin gelişmesi, akıllı telefonların ortaya çıkması ve arama motorları gibi geniş 
yelpazeli bilgi kümelerinin kullanıma açılmasıyla tartışılmaya başlanmıştır. Hem doğa hem de sosyal bilimlerin odak konularından biri hâline dönüşmüştür. Yapılan çalışma çerçevesinde siyasal iletişim alanı açısından bakıldığında büyük verinin sağladığı veri bolluğu ve çeşitliliği sayesinde siyasal kampanyalar, büyük ölçekli veri kümelerini kullanarak spesifik kitlelere ulaşmaya, mesajları hızlı şekilde iletmeye ve mesajların etkisini artırmaya çalışmaktadır. Bu anlamda veri odaklı kampanyacılık anlayışı ilk olarak ABD'de Obama'nın 2012 seçimlerinde ortaya çıkmış ve daha sonra yayılmaya başlamıştır. Temelde bu kampanyalarda oy verenlerin kişisel verilerinin kullanılmasıyla siyasal davranışları ve etkileşim düzeyleri temel alınmaktadır. Diğer taraftan Kuzey Amerika'dan farklı olarak Avrupa ülkedelerinde ise kişisel verilerin gizliliği ve korunması ile ilgili yasal düzenlemelerden dolayı veri odaklı kampanyalar daha yavaş ve farklı açılarda gelişmektedir (Bennett, 2016).

Veri odaklı kampanyacılık, yeni bir kavram ve uygulama olduğundan, literatürde çok sayıda örneğe rastlanmamaktadır. Bu bağlamda araştırma sonucunda ABD, Birleşik Krallık, Almanya ve Kenya örnekleri öne çıkmaktadır. ABD'de Obama'nın kampanyalarında Facebook algoritmasının ve kullanıcı verilerinin hedef grup belirleme ve gönüllülük faaliyetlerini destekleme anlamında etkin şekilde kullanılmasına karşın, Trump'ın kampanyasında üçüncü taraflardan alınan kişisel veriler, mikro-hedefleme stratejisi ve sosyal medya algoritmalarının yönetilmesiyle yürütülen tanıtım faaliyetleri etkili olmuştur. Birleşik Krallık örneğinde Experian şirketinin sunduğu 67 kategorilik veri tabanı, Almanya'da "mobilizasyon endeksi" ile verilerin çoklu korelasyon işlemi kampanya süreçlerini olumlu şekilde etkilemiştir. Diğer taraftan Kenya'da kişisel verilerin etnik ayrımcılığı körükleyen bir biçimde kötü kullanımı ortaya çıkmıştır. Bu da kişisel verilerin korunması ve gizliliği gibi hassas konularda yasal düzenlemelerin eksikliğine işaret etmektedir. Türkiye'de ise kişisel verilerin korunmasına yönelik hukuki mevzuat 6698 numaralı Kanun içermektedir.

Çalışma kapsamında siyasal kampanyalarda etkili veri kullanımına ilişkin bir yol haritası sunulmuştur. Bu anlamda veri odaklı kampanyacılık anlayışının daha iyi anlaşılması ve uygulanabilmesi açısından hem bir kavram haritası hem de aşamaların betimlendiği bir süreç önerilmiştir. Kavram haritası anlamında yedi ana bileşen vurgulanmıştır: veri toplanması, veri analizi, hedef grup belirleme, strateji geliştirme, tahminsel model oluşturma, sosyal medya algoritmaları ve gerçek zamanlı süreç izleme/değerlendirme. Öne çıkarılan kavramların bir kampanya sürecinde nasıl uygulanması gerektiğine ilişkin üç aşamalı bir strateji önerilmiştir. Bu stratejiye göre ilk aşamada veri toplanması ve analizi gibi faaliyetlerin siste- 
matik şekilde gerçekleştirilmesi gerekmektedir. İkinci aşama ise kampanya için hedef grup/ların belirlenmesi, mevcut stratejinin geliştirilmesi ve kullanıcıların siyasi tutum ve davranışlarını ölçümleyen tahminsel modellerin uygulanmasını içermektedir. Son aşama değerlendirme aşamasıdır. Bu süreçte sosyal medya algoritmalarının tanıtım faaliyetlerinin etkinleştirilmesi açısından başarıyla yönetilmesi ve gerçek zamanlı kampanya etkisi değerlendirmesi gerçekleşmektedir. Elde edilen sonuçların gelecek seçim süreçleri için kullanılmak üzere bir veri tabanında depolanması gerekmektedir.

Seçim kampanyalarında büyük verinin "gücünden" yararlanarak etkili bir veri kullanımı için öncelikle alanında yetkin veri uzmanlarının ya da veri firmalarının sürece dâhil edilmesi gerekmektedir. Aksi takdirde verilerin sistematik toplanması ve analizi gerçekleşemeyecektir. Diğer taraftan kampanyalarda kişisel verilerin kullanımı önemli ve hassas bir konudur. Bu anlamda ilgili kanunlara ve yasal düzenlemelere uygun şekilde hareket edilmesi gerekmektedir. Yapılan bu çalışma ile literatürde yeni çalışılmakta ve gelişmekte olan bir konu olan veri odaklı kampanya anlayışını ele almaktadır. Etkili veri kullanımına ilişkin sunulan yol haritasının gelecek çalışmalara ve uygulamalara katkı sağlayacağı düşünülmektedir.

\section{Kaynakça}

Anstead, N. (2017). Data-Driven Campaigning in the 2015 United Kingdom General Elections. The International Journal of Press/Politics, 22 (3), 294-313. DOI: $10.1177 / 1940161217706163$

Aragona, B. ve De Rosa, R. (2019). Big data in policy making. Mathematical Population Studies, 26 (2), 107-113, DOI: 10.1080/08898480.2017.1418113

Balcı, Ş. ve Sarıtaş, H (2015). Facebook ve Siyasal Katılım: 2014 Yerel Seçimleri Araştırması. Türkiyat Araştırmaları Dergisi, 37, 511-535.

Baldwin-Philippi, J. (2017). The Myths of Data-Driven Campaigning. Political Communication, 34 (4), 627-633, DOI: 10.1080/10584609.2017.1372999

Baldwin-Philippi, J. (2019). Data Campaigning: Between Empirics and Assumptions. Internet Policy Review, 8 (4), 1-18, DOI: http://dx.doi.org/10.14763/2019.4.1437

Bennett, J. C. (2016). Voter Databases, Micro-Targeting and Data Protection Law: Can Political Parties Campaign in Europe as They do in North America? International Data Privacy Law, 6 (4), 261-275

Bimber, B. (2014). Digital Media in the Obama Campaigns of 2008 and 2012: Adaptation to the Personalized Political Communication Environment. Journal of Information Technology \& Politics, 11 (2), 130-150, DOI: 10.1080/19331681.2014.895691

Breiter, A., \& Hepp, A. (2018). The Complexity of Datafication: Putting Digital Traces in Context. İçinde A. Hepp, A. Breiter and U. Hasebrink (eds.), Communicative Figurations. Bremen: Palgrave Macmillan, 387-407 
Dobber, T., Trilling, D., Helberger, N. ve de Vreese, C. (2017). Two Crates of Beer and 40 Pizzas: The Adoption of Innovative Political Behavioural Targeting Techniques. Internet Policy Review, 6(4), 1-26, DOI: 10.14763/2017.4.777

Dommett, K. (2019). Data-Driven Political Campaigns in Practice: Understanding and Regulating Diverse Data-Driven Campaigns. Internet Policy Review, 8 (4): 1-19.

Evren, B. F. (2015). Bir Siyasal İletişim Aracı olarak İnternet Sitesi Kullanımı: 2014 Cumhurbaşkanlığı Seçimi. Journal of Yasar University, 10 (39), 6655-6611

Gutierrez, M. (2018). Data Activism and Social Change. Madrid: Palgrave Macmillan İkiz, Ö.Ö., Sobacı, Z, M., Yavuz, N. ve Karkin, N. (2014). Political Use of Twitter: Teh Case of Metropoitan Mayor Candidates in 2014 Local elections in Turkey, ICEGOV 2014, 27-30 Ekim 2014, Grumaraes, Portekiz.

İnanç, S. A., Bozdemir, Y. ve Doğan, E. (2020). Bir Siyasal iletişim Aracı olarak Sosyal Medyada 2019 Yerel Seçimlerindeki Muhtar Adaylarının Instagram Kullanımları. Anadolu Akademi Sosyal Bilimler Dergisi, 2 (1), 141-162.

Karunian, A. Y., Helka, H. ve Söderholm, A. (2019). Data Profiling and Elections: Has Data-Driven Political Campaign Gone Too Far? Udayana Journal of Law and Culture, 3 (1), 95-122. DOI: https://doi.org/10.24843/UJLC.2019.v03.i01.p05.

Kitchin, R. (2014). Big Data, New Epistemologies and Paradigm Shift. Big Data \& Society, 1-12. DOI: $10.1177 / 2053951714528481$

Kiukkonen, N., Blom, J., Dousse, D., Gatica-Perez, D. ve Laurila, J. (2010). Towards Rich Mobile Phone Datasets: Lousanne Data Collection Campaign, Erişim Adresi: https://www.idiap.ch/ gatica/publications/KiukkonenBlomDousseGaticaLaurila-icps10.pdf (erişim tarihi: 20.09.2020)

Kreiss, D. (2016). Prototype Politics: Technology-İntensive Campaigning and The Data of Democracy. New York: Oxford University Press.

Kruschinski, S. ve Haller, A. (2017). Restrictions on Data-Driven Political Micro-Targeting in Germany, Internet Policy Review, 6 (4), 1-23, DOI: http://dx.doi. org/10.14763/2017.4.780

Lewis, S. C., ve Westlund, O. (2015). Big data and journalism. Digital Journalism, 3(3), 447466. DOI: https://doi.org/10.1 080/21670811.2014.976418

Magin, M., Podschuweit, N., Haßler, J., ve Rußmann, U. (2017). Campaigning in the Fourth Age

of Political Communication. A Multi-Method Study on the Use of Facebook by German and Austrian Parties in the 2013 National Election Campaigns. Information, Communication \& Society, 20 (11), 1698-1719. DOI: doi:10.1080/136 9118X.2016.1254269

Moffat-Hannah, K. (2019). Algorithmic Risk Governance: Big Data Analytics, Race and Information Activism in Criminal Justice Debates. Theoretical Criminology, 23 (4), 453-470. tps://doi.org/10.1177/1362480618763582

Nickerson, W. D. ve Rogers, T. (2014). Political Campaigns and Big Data. Journal of Economic Perspectives, 28 (2), 51-74.

Noh, K. S. (2013). A Exploratory Study on Big Data BAsed Election Campaigning Strategy Model in South Korea. The Journal of Digital Policy and Management, 11 (12), 113-120.

Northcott, R. (2020). Big Data and Prediction: Four Case Studies. Studies in History and Philosophy of Science, 81, 96-104. 
Rubinstein, S. I. (2014). Voter Privacy in the Age of Big Data. Wisconsin Law Review, 8, 861-936.

Sağıroğlu, S., ve Sinanc, D. (2013). Big data: A review. 2013 International Conference on Collaboration Technologies and Systems, San Diego, USA, 42-47.

Tufekci, Z. (2014). Engineering the public: Big data, surveillance and computational politics. First Monday, 19(7). Erişim Adresi: http://firstmonday.org/ojs/index. $\mathrm{php} / \mathrm{fm} / \mathrm{article} / \mathrm{view} / 4901$ (Erişim tarihi: 15.09.2020)

Wiesenberg, M., Zerfass, A ve Moreno, A. (2017) Big Data and Automation in Strategic Communication, International Journal of Strategic Communication, 11 (2), 95-114, DOI: 10.1080/1553118X.2017.1285770

Zararsız, F. Ö. Ve Sönmez, B. (2018). 2017 Anayasa Değişikliği Referandumu Kampanya Sürecinde Twitter Kullanımı. İletişim, Kuram ve Araştırma Dergisi, 46, 207-221.

Zeybek, B. (2020). Siyasal Kampanyaların Geleceğinde Veri-Temelli Yönelimler. Akdeniz İletişim Dergisi, 33, 54-72. 


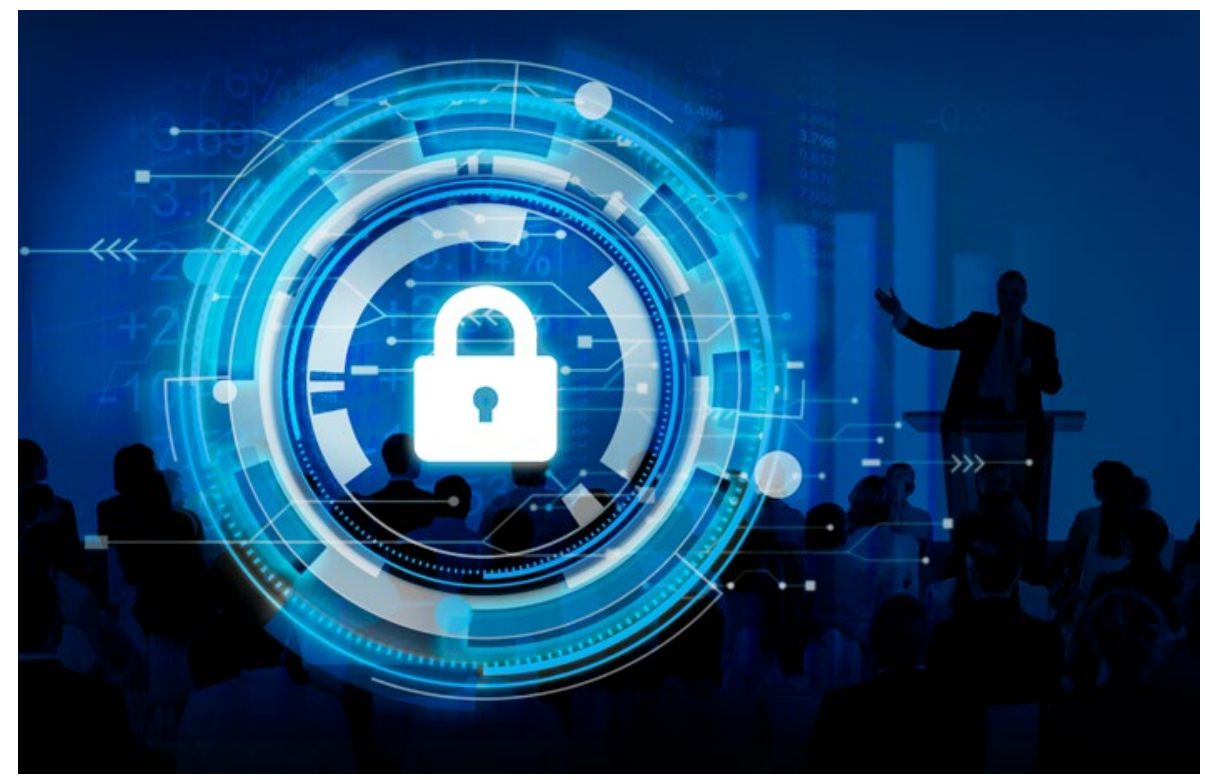

Dijital korumanın önemi, Freepik 